\title{
A Seven-Step Framework for Encouraging Deeper Learning in Business Education
}

By

Mark A. Serva, University of Delaware

Ellen F. Monk, University of Delaware

$\mathrm{T}$ his essay examines how business school professors can encourage deeper learning in their students. Business faculty (and academia in general) are improving student involvement by using pedagogies of engagement (e.g., problem-based learning, team-based learning, project-based learning) or integrating techniques that improve engagement (e.g., flipped classes, reflective writing). Adoption of these approaches is a step forward, but little has been written about the specific factors across techniques and pedagogies that can actually deepen learning. This essay utilizes a seven-point framework for deeper learning, applies it to the teaching of managerial decision-making, and makes recommendations for fostering deeper learning among business school students. The authors cite specific examples of business
What should business school professors do encourage deeper learning in their students? Using a framework for deeper learning, the authors convey a method for fostering educational excellence among business students. school teaching that illustrate traditional methods and deeper learning methods. The goal of this paper, therefore, is to present seven factors (Ambrose et al., 2010) that work to deepen student learning-independent of any specific pedagogy or adopted technique. These solutions span across any business school discipline and can be easily integrated into a college class to foster deeper learning.

Keywords: Learning, Pedagogy, Teaching, Formative assessment, Summative assessment, Deeper Learning

Copyright ( ) 2021, Mark A. Serva, Ellen F. Monk. This article is published under a Creative Commons BY-NC license. Permission is granted to copy and distribute this article for non-commercial purposes, in both printed and electronic formats 
As university tuition rises and society increasingly scrutinizes the value of a college education, the following questions seem more relevant than ever: How can business school faculty encourage students to go beyond surface learning and adopt practices that foster deeper learning? And how can students utilize these techniques to make better decisions within a professional context?

Business faculty (and academia in general) are beginning to improve student learning by using pedagogies of engagement-e.g., problem-based learning, team-based learning, POGIL (process oriented guided inquiry learning) or techniques (e.g., flipped classes, reflective writing) that purport to improve student learning. Adoption of these approaches is a step forward, but little has been written about the specific factors across techniques and pedagogies that can actually deepen learning. Independent of the steps provided within-say-problem-based learning-what can instructors do to improve student understanding? The goal of this paper, therefore, is to present seven factors (Ambrose et al., 2010) that work to deepen student learning-independent of any specific pedagogy or adopted technique. These solutions span across any business school discipline and can be easily integrated into a college class to foster deeper learning.

\section{Review of Research: What is}

The definition of "learning" varies, denoting different levels of understanding. The term "learning" can denote, for example, a surface level of understanding, exemplified by students who memorize content the night before to pass an exam. A goal of this paper, however, is to explore how to achieve the deeper learning that is reflected in mastery, and we define this approach to "learning" later in this section.

With more high school students attending tertiary institutions (Kuh et al., 2005), "good teaching is getting most students to use the higher cognitive level processes that the more academic students use spontaneously" (Biggs, 2003, p. 3). One job of educators is to narrow the gap between the exceptional learners and the majority of learners (Figure 1) (Biggs, 2003). An approach that has been widely accepted is a movement away from objectivist approaches and toward constructivist approaches (Dean \& Forray, 2015; Dewey, 1902; Piaget, 1971). Objectivist models support knowledge transfer, where learning is characterized as a bank. Faculty "deposit" knowledge in students' brains, which is then "withdrawn" on exams (Freire, 1990). Educational research, however,

High-level engagement

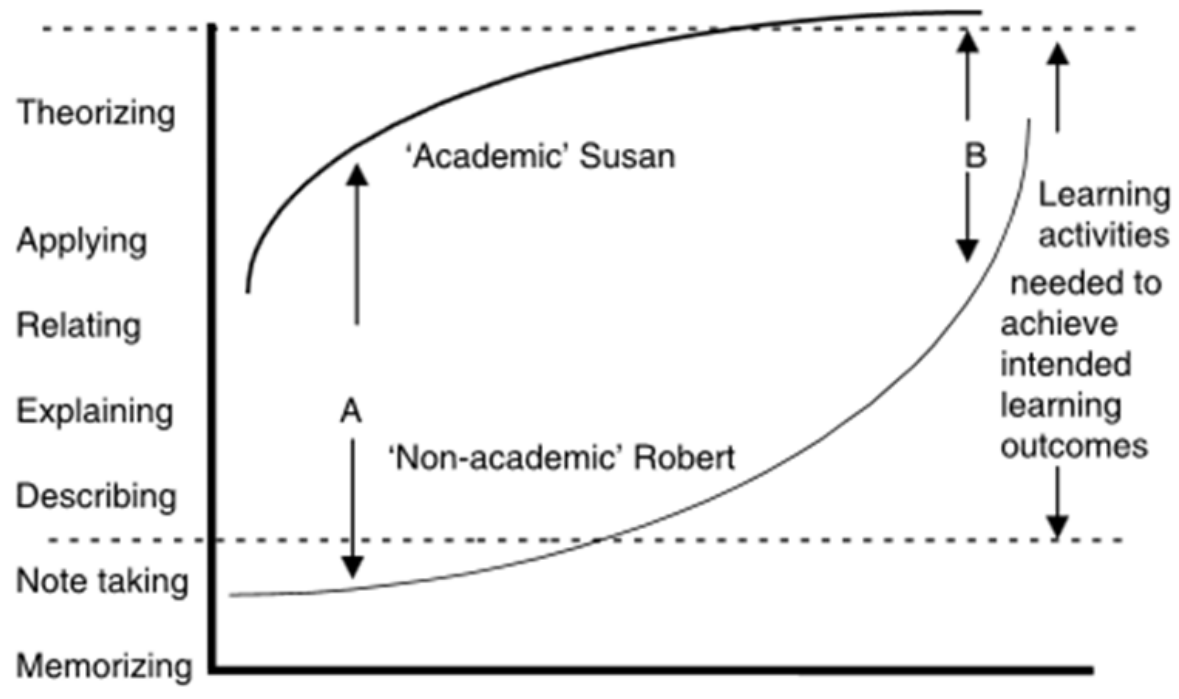

Low-level engagement

Passive $\longleftarrow$ Level of student activity elicited $\longrightarrow$ Active

(e.g. the standard lecture)

(e.g. problem-based learning)

Teaching method

Figure 1: Bridging the Gap between Low and High Performing Students (Biggs, 2003) 
has indicated that the knowledge transfer model is inefficient and ineffective-even more so if the goal truly is deeper learning (Freeman et al., 2014).

Objectivist practices-as illustrated in Figure 1focus on passive techniques, such as lecture. Such objectivist approaches have therefore been characterized as "surface learning" strategies (Crooks, 1988). Within the classroom, the objectivist model encourages passive learning techniques, such as note-taking. Students are expected to peruse the textbook, create flash cards, and outline the chapter, all of which reinforce surface learning (Dehler et al., 2010).

Students passively listening to a lecture continues to be the dominant form of instruction, in some institutions (Carey, 2015; Davis \& Arend, 2013; McKeachie, 1990), even though evidence indicates that lecture does not instill deep learning and mastery (McKeachie, 1990):

"Really deep learning is a process that inevitably is driven by the learner, not by someone else. And it always involves moving back and forth between a domain of thinking and a domain of action. So having a student sit passively taking in information is hardly a very good model for learning; it's just what we're used to (O'Neil, 1995, p. 20)."

Even if the process of rote learning was never effective, the value of information recall has dramatically declined. Unlike previous generations, today's managers can access facts instantaneously. Instead of simply knowing facts, managers need to learn how to best use the information to formulate decisions. Supporting this idea, constructivist models posit that possession of knowledge is not synonymous with learning. Instead of an objective (or "true") reality, constructivism posits that knowledge is created in the mind of the individual, and the resulting mental models will differ across individuals (Jonassen et al., 1993). The constructivist learning model posits that for students to incorporate concepts into their long-term memory, they must interact extensively with the material. Contrary to the objectivist view, learning should not primarily be about acquiring facts; instead, learning should be about acquiring skills, developing critical and/or creative thinking abilities, solving problems, changing feelings and behaviors, and/or improving professional judgment (Davis \& Arend, 2013).

We summarize the contrasts between objectivist ("surface learning") and constructivist ("deep learning”) approaches in Table 1.

\section{The Theory}

To frame our exploration for the need for deeper learning, we adopt the definition of learning from the book How Learning Works (Ambrose et al., 2010, p. 3):

- Learning is a process, not a product. However, because the process takes place in the mind, [educators] can only infer that it has occurred from students' products.

- Learning involves change in [students'] knowledge, beliefs, behaviors, and/or attitudes. This change unfolds over time; it is not fleeting but rather has a lasting impact on how students think and act.

- Learning is not something done to students, but rather something students themselves do. It is the direct result of how students interpret and respond to their experiences-conscious and unconscious, past and present [emphasis original].

Ambrose et al's definition aligns well with other theoreticians, who have defined the three criteria for learning as (1) A behavior or ability change; (2) this change resulting from some practice; and (3) this change is long-lasting (Shuell, 1986). These points are clearly consistent with a constructivist model of learning, which will guide our arguments throughout this essay. The following section examines the three parts of Ambrose et al.s definition of learning in more detail.

Table 1: Contrast between Deep and Surface Learning

\begin{tabular}{|l|l|}
\hline \multicolumn{1}{|c|}{ Deep Learning Approach } & \multicolumn{1}{|c|}{ Surface Learning Approach } \\
\hline An intention to develop personal understanding & $\begin{array}{l}\text { An intention to be able to reproduce content as } \\
\text { required }\end{array}$ \\
\hline $\begin{array}{l}\text { Active interaction with the content, particularly } \\
\text { in relating new ideas to previous knowledge and } \\
\text { experience }\end{array}$ & Passive acceptance of ideas and information \\
\hline $\begin{array}{l}\text { Linking ideas together using integrating princi- } \\
\text { ples }\end{array}$ & $\begin{array}{l}\text { Lack of recognition of guiding principles or } \\
\text { patterns }\end{array}$ \\
\hline Relating evidence to conclusions & Focusing learning on assessment requirements \\
\hline
\end{tabular}


Learning is a process. Faculty assume that if students do well on a test, they have achieved mastery of the material. Surprisingly, such an assumption is often not warranted. Research has demonstrated, for example, that much of what is memorized is quickly forgotten (Roedinger, 2014): hence, exam grades may only reflect what students knew before the information was forgotten. "Although it is important to know... whether a student can actually perform the skill...summative evaluation doesn't contribute much, if at all, to the actual process of learning" (Davis \& Arend, 2013, p. 60).

In contrast to graded assignments, formative assessment-in the form of constructive feedback-is much more conducive to learning. Formative assessment is woefully underutilized in academia (Black \& William, 1998; Cardelle \& Corno, 1981). Formative assessment tends to be process-oriented, in that students integrate feedback to improve previous work and build on previous efforts by correcting mistakes (McKendree, 1990). In this manner, formative assessment can become a longitudinal indication of learning, can instill changes in long-term memory, and can be more of a more valid indicator of learning than an exam (Harper \& Quaye, 2009).

Learning has a lasting impact. The second part of Ambrose et al's definition of learning notes that for students to learn, a permanent change in the students' mental model must have occurred. This point directly contrasts to objectivist view of education.

Faculty might ask themselves: what pervasive understandings do I want my students to achieve? Phrased more informally, what do I want my students to know and be able to do months after the course concludes? In a marketing course, for example, students may 'understand' stakeholder analysis, but still fail to understand that it could guide them in launching a product. If stakeholder analysis represents a desired pervasive understanding, more time may be needed for students to understand its broader context. This reflects a major weakness of the objectivist learning model: the efficiency of the knowledge transfer process is often given priority over the additional repetition and clarification that is necessary to understand a concept's broader context (Argote \& Ingram, 2000; Demirer \& Sahin, 2009).

Learning is what students do. The last point in the definition reinforces that to improve learning, we need to focus more on what the students-not the instructors-do (Biggs, 2003) (Shuell, 1986): "Learning results from what the student does and thinks and only from what the student does and thinks. The teacher can advance learning only by influencing what the student does to learn" (Herbert Simon, as quoted in Ambrose et al., 2010, p. 1).

The differentiation of the terms "teaching" (what teachers do) and "learning" (what students do) is important: for students to construct a lasting mental model, students must teach themselves (Dehler et al., 2010). The educator's primary responsibility is to create a supportive and creative learning environment (Fink, 2013) that motivates students to want to learn. Ironically, faculty who focus on teaching may actually be undermining student learning: "teaching must often stop before learning can begin. The converse is surely true: it does not follow that anybody is learning because somebody is teaching, even teaching well" (Sotto, 1994, p. 144). Faculty also conflate the terms "teaching" and "learning": that is, they assume if they teach (cover) the content, students have learned the content.

Research indicates that covering more content dilutes students' attention and encourages surface learning strategies (Schwartz et al., 2008). In effect, the more time the instructor tells students what they need to know, the less time students will have to actively engage in the material, which again encourages surface learning (Schwartz et al., 2008). This essay therefore relies on the premise that adoption of constructivist pedagogies can improve student learning by encouraging students to construct their own mental model of the problem or concept.

\section{Applications of the Theory: The Guiding Framework}

To better understand how to encourage deeper learning in business schools, we rely on a seven-point framework (Ambrose et al., 2010) to spur ideas for achieving deep learning:

1. Students' prior knowledge can help or hinder learning.

2. How students organize knowledge influences how they learn and apply what they know.

3. Students' motivation determines, directs, and sustains what they do to learn.

4. To develop mastery, students must acquire component skills, practice integrating them, and know when to apply what they have learned.

5. Goal-directed practice coupled with targeted feedback are critical to learning.

6. Students' current level of development interacts with the social, emotional, and intellectual climate of the course to impact learning.

7. To become self-directed learners, students must learn to monitor and adjust their approaches to learning.

These seven principles were chosen because they are not tied to a specific pedagogical approach and map well to management decision making across business disciplines. The seven principles also have a practical element in that they provide specific recommendations for business faculty to foster deeper learning in their students. For these reasons, we explore the seven principles within a business school 
context and use the framework to provide specific suggestions for improving student learning.

\section{Principle 1: Students' Prior Knowledge Can Help or Hinder Learning}

Students are never a blank slate. They draw on experiences from other courses, internships, and life experiences. Prior knowledge, however, can both help and hinder students (Shuell, 1986). Ambrose et al. (2010) outlines a road map to guide instructors through the topic of prior knowledge. This fourstep roadmap begins with (1) activate accurate prior knowledge, (2) address insufficient prior knowledge, (3) help students recognize inappropriate prior knowledge, and (4) correct inaccurate knowledge.

The first step involves identifying and priming student extant knowledge. This is critical, since students learn faster and retain concepts longer when they can connect new material to existing knowledge (Bransford \& Johnson, 1972, p. 188; Resnick, 1983; Vygotsky, 1978). However, asking students to recall concepts and expertise from an earlier class is usually not sufficient. Instead, a more effective approach is to integrate a priming exercise to activate the prerequisite concepts (Bransford \& Johnson, 1972; Dooling \& Lachmann, 1971, p. 191; Gick \& Holyoak, 1980). Such an exercise should involve priming not only the relevant declarative knowledge (reviewing an example of crosstabs), but also the procedural knowledge (breaking students into teams, and exploring the relevant "what", "when", and "how" questions).

Addressing insufficient prior knowledge is meant to fill in the gaps where previous educational endeavors lack. Most business schools require foundational courses, but faculty still complain that students later fail to remember the information. A capstone projects class, for example, might require students to integrate information from the past four years. If the instructor in the foundational project management class described how to design a relational database, however, students may be limited in their ability to do it. This example also illustrates the difference between declarative knowledge (I know it) versus procedural knowledge (I know what it is; I know when I should do it; and I know how to do it) (de Jong \& Ferguson-Hessler, 1996). Conversely, students may also know how to do something, but not really understand what they know. One example is generating a statistical analysis, such as crosstabs. Students may be comfortable with the process for creating the analysis but may be unable to transfer that understanding to explain what the output represents (or under what circumstances such an analysis is appropriate).

Instructors need to assess (third step) their students' prior knowledge to ensure that the knowledge is correct. The presence of prior knowledge can also impede the acquisition of new knowledge. Students often assume, for example, that what they know is valid across all contexts. Accounting students, for example, may have been taught that a company should have a quick ratio of at least one, but fail to understand that inventory-intensive industries (e.g., retail stores) will often fall below the 1.0 level. Database students who learn about third normal form may assume that denormalized tables are "wrong," without understanding the gained efficiencies. Unless a class provides such context, students will tend to gravitate toward the known, instead of researching a contingency approach that considers the nuances of the analysis.

Finally, any prior incorrect knowledge must be corrected. It's important to allow sufficient time for students to understand that their knowledge is incorrect. Suggestions such as making and testing predictions and justifying reasoning (Ambrose et al., 2010) are methods to correct such inaccuracies. Another suggestion is to allow students to use the correct knowledge in multiple applications, because reinforcement can correct problems that might not be absorbed by simple discussion (Djoub, 2020). For example, in an upper-level business school database class, one of the authors repeatedly uses data modeling exercises in class encouraging the students to conform to the more formalized method of creating entity-relationship diagrams, rather than rough and sometimes inaccurate ways of conveying data models that might have been used in prerequisite classes. Reinforcing correct prior knowledge removes the barriers that incorrect prior knowledge might have thwarted and offers students a full learning experience.

\section{Principle 2: How students organize knowledge influences how they learn and apply what they know.}

Although Principle 1 (P1) addresses how prior knowledge affects learning, how students organize their learning also has implications for learning. As discussed in Ambrose et al. (2010), this organization might include temporal (low cash flows and liquidity can inhibit a company's ability to pay its bills), concepts that share meaning (in programming, forloops and while loops can both accomplish the same task), and perceptual similarities (relational data models and class diagrams represent similar, but distinctive views of a system).

The challenge for instructors is creating an effective method for assisting students in organizing knowledge effectively. Many instructors rely on PowerPoint at the start of a course module to assist with that organization. In practice this approach is ineffective for several reasons. First, students generally cannot pay attention through a full lecture, which inhibits knowledge and understanding. Next, lectur- 
ing at the start of a module can demotivate students from reading the required material.

Team-based learning is a pedagogy that provides the RAP (readiness assurance process), which is a unique and effective method for not only activating students' prior knowledge (Principle 1), but also assisting in the organization of the new knowledge (Michaelsen et al., 2004). On the first day of each course module, students are assigned readings, videos, and other materials. Before any lecture or exercises on the module occurs, students take a ten-question multiple choice quiz. This quiz is the "iRAT," or the individual readiness assurance test. Immediately after the iRAT, the instructor administers the tRAT, or the team readiness assurance test. Working in teams, students discuss the question, discuss the merits of different responses, and eventually reach a consensus. All team members receive the same score, and the final score is the average of the two quizzes. In the final phase, the instructor leads a discussion on the different questions and answers. Such a discussion can include relating the new material to previous topics, reviewing important (but difficult) foundational concepts, and answering students' questions on why they missed specific questions.

The RAP is a highly effective method for assisting students in constructing foundational knowledge. In addition to foundational concepts, the structure and order of the traditional business curriculum can also affect how students structure their mental models. Students start by learning foundational skills (e.g., principles of programming). Because foundational concepts are taught in distinct classes, students' mental models will lack integrative understanding. The order of the concepts presented can also confuse. In MIS, for example, students learn programming in their freshman year, and analysis and design concepts in their junior or senior year. In contrast, on a real project, coding occurs only after analysis and design.

In an example provided by a student to one of the authors (Serva), a physics professor lectured on the various formulas required to understand trajectories and vectors. Homework assignments were "plug and chug": the exercise provided the value of the parameters, and the students simply needed to use the provided parameters to find the designated answer. On the exam, however, the students were expected to solve a real problem-that is, estimate the values of the parameters and find when two items collided in mid-air. Students did very poorly on the exam because they had organized the knowledge in a specific manner. They associated solving a problem with simply plugging in values into an equation. Students would learn more by understanding how the concepts integrate, and the instructor could have facilitated understanding by providing examples that allowed them to organize the material in different ways (personal communication, 2019).

This example illustrates the importance of not only providing the components and foundational knowledge, but also providing opportunities to practice integrating those components so that students can experience different ways they combine into a whole. Unfortunately, the component-driven approach often dominates. A senior capstone class (e.g., Business Strategy) can improve integrative understanding, since students must gain an understanding of how the concepts within the curriculum come together in a cohesive whole. Students will make better decisions when schools learn that integration of component skills is a distinct skill that must be learned.

In summary, although faculty must structure curricula to facilitate student learning, it is important to recall that this structure can also affect students' mental models and their ability to achieve deeper learning. Faculty can help students organize their knowledge by providing greater context, especially for more difficult topics. A contextual flowchart or template, for example, may illuminate how a complex, hierarchical process unfolds over time. Alternatively, after a RAP quiz, students could create a concept map (Novak \& Gowin, 1996) that documents their understanding of the new concepts, as well as how they interact with prior material. Such models create formative opportunities for comparing and contrasting one's perceptions with the perceptions of others and facilitates the movement toward deeper forms of understanding.

\section{Principle 3: Students' motivation deter- mines, directs, and sustains what they do to learn.}

Motivation is the personal investment a person has in reaching a desired outcome (Maehr \& Meyer, 1997). Previous studies have found that fostering student motivation is one of the most important things faculty can do to improve learning (Bolkan \& Goodboy, 2010; Christophel, 1990; Deci \& Ryan, 2000); consistent motivation is a key to learning (Williams \& Williams, 2011); and motivated students are more satisfied with their educational experiences and are more likely to graduate (Kuh et al., 2005).

Students' level of motivation is a function of their expectancies and the perceived value of the learning goals (Ambrose et al., 2010). An expectancy is the student's perception of the likely outcome (Bandura, 1997). Expectancies in turn depend on the students' perception of their own efficacy to complete the task, as well as the relevant outcome expectancies. For example, if students believe they lack the skills to do well on a test, they will spend less time preparing. Even if students believe they have the requisite skills, if the perceived expectancies are negative (e.g., the test will be graded unfairly, the tests 
do not reflect the covered material), motivation will drop. Students' expectancy and value are moderated by the perceived supportiveness of the learning environment. Students will be motivated to achieve a class goal only if they see value in the goal, have high levels of efficacy, and perceive a supportive learning environment (Ambrose et al., 2010) (Table 2).

An important consideration in fostering (or dampening) student motivation, therefore, is the clarity of faculty assessment policies and practices (Hansen, 1989; Ford, 1992). Ex post grading, for example, is a common practice that can undermine student motivation. In ex post grading, faculty provide the grading standards after assignments have been graded. Students are likely to perceive ex post grading as unpleasant and punitive-not supportive and positive. Such a practice reduces student understanding of instructor expectations, and reinforces the idea that grades are arbitrary and foisted upon them by their instructors (Singleton-Jacson et al., 2010).

Unclear assessment practices-such as ex post grading-can therefore greatly reduce student efficacy and perceptions of instructor supportiveness, undermining student motivation (Hansen, 1989; Ford, 1992). Even if students see value in the course, unclear or unfair grading practices will result in feelings of hopelessness, characterized by defeatism, disengagement from the class, and absenteeism (common occurrences in college classes, unfortunately) (Table 2). Students who can maintain their self-efficacy when faced with low grades may become defiant-e.g., challenging grading standards in a confrontational manner. Students who eventually come to see no value from the experience will manifest a rejecting or evading attitude-completely disengaging from the class (e.g., texting with friends, sleeping).

To foster student motivation, therefore, faculty need to clarify their grading standards. One approach is the increased use of rubrics, which can greatly improve both reliability and validity in grading (Jonsson \& Svingby, 2007). Rubrics also make faculty expectations and grading criteria more explicit, especially when distributed when the exercise is assigned (Jonsson \& Svingby, 2007). Most college classes give students no opportunity to learn from mistakes (e.g., to retake an exam or to resubmit homework). Such practices not only foster perceptions of instructor supportiveness, but they also encourage students to learn from previous misconceptions.

Beyond clear assessment policies, there are other methods instructors can adopt to manipulate the three levers and improve student motivation. Practice exams provide a basis for students to study, as well as remind them of important concepts. Instead of simply providing example exam questions, instructors should encourage student teams to work together, and then perhaps present their answer to the class. Struggling students will not only fill gaps in their understanding by learning from their peers but will improve their self-efficacy before the exam (Michaelsen et al., 2004). Faculty sometimes bemoan "dumb questions," but faculty should consider that questions on basic concepts present an opportunity. Confusion in basic concepts exposes a fundamental gap in students' learning - and therefore, a possible blind spot in the instructor's teaching. It also exposes a student who had the courage to speak up, but also one who is significantly behind his peers (and such a gap may inhibit that student from progressing). One suggestion is for the instructor to meet with the student to communicate her willingness to provide

Table 2: Three Levers of Motivation

\begin{tabular}{|c|c|c|c|c|c|}
\hline & \multicolumn{4}{|c|}{ Learning Environment } \\
\hline & & \multicolumn{2}{|c|}{ Not Supportive } & \multicolumn{2}{|c|}{ Supportive } \\
\hline & & $\begin{array}{l}\text { Students Don't See } \\
\text { Value }\end{array}$ & Students See Value & $\begin{array}{c}\text { Students Don't See } \\
\text { Value }\end{array}$ & Students See Value \\
\hline 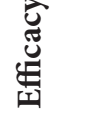 & 草 & REJECTING & HOPELESS & REJECTING & FRAGILE \\
\hline 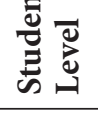 & 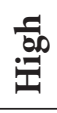 & EVADING & DEFIANT & EVADING & MOTIVATED \\
\hline
\end{tabular}

Rejecting: Characterized by disengagement, apathy, alienation.

Evading: Completing minimal amount of work, texting in class

Defiant: Disrespect, "I'll show you" attitude

Fragile: Feigning understanding, hiding in class, making excuses

Hopeless: No expectation of success, disengagement from class, absenteeism

from Ambrose et al. (2010), p. 80 
assistance in catching up (and fostering perceptions of supportiveness).

Similarly, instructors should seek opportunities to provide constructive feedback on students' performance. Faculty can also provide opportunities by providing challenging homework assignments but allowing students to start work on the assignments in class in teams. The feedback and discussion throughout the class provides scaffolding for students to complete the task on their own. These sessions also allow the faculty member to engage in triage during class-that is, encouraging the students who need the help the most.

In a business curriculum, a supportive learning environment might include outreach to businesses that might be potential employers. Students often see value in connecting to these business leaders in the real world. One motivating activity is to conduct a type of speed-dating with these business leaders (Chan \& Murphy, 2010). Students are invited to have lunch with the leaders and then take five minutes for oneon-one chats, as with speed-dating.

To motivate students and increase their desire to learn, instructors should foster a sense of community. In management classes, supportive professors (Berkow, 2021) build community in the classroom by making students feel comfortable because students learn best when they feel like they belong and are included. Students also learn from one another and need those connections to do so. A student in a management class who feels like they belong can be willing to ask questions and be willing to make mistakes. Research into building community found that female students who dropped out of a finance major to move into accounting did so because they felt like they didn't belong. A professor's job is to facilitate conditions that make students feel like they belong and can be motivated to learn, leading them to the most enriching pedagogical experience.

\section{Principle 4: To develop mastery, stu- dents must acquire component skills, practice integrating them, and know when to apply what they have learned.}

Mastery is the attainment of a high degree of competence within a particular discipline (Ambrose et al., 2010). To achieve mastery, a person must achieve the following (Ambrose et al., 2010, p. 95):

- Competence in component skills

- In addition to how, an understanding of when and why the component skills are used and be able to transfer that understanding to different situations.

- Practice integrating the component skills within appropriate contexts.

Business school faculty who teach upper-level classes can forget that students may have studied the concepts six to twelve months in the past, and that the context may differ. For example, if Gantt charts are taught as a project management tool in their sophomore year, students may understand what they are and how to do them. But on an actual project,

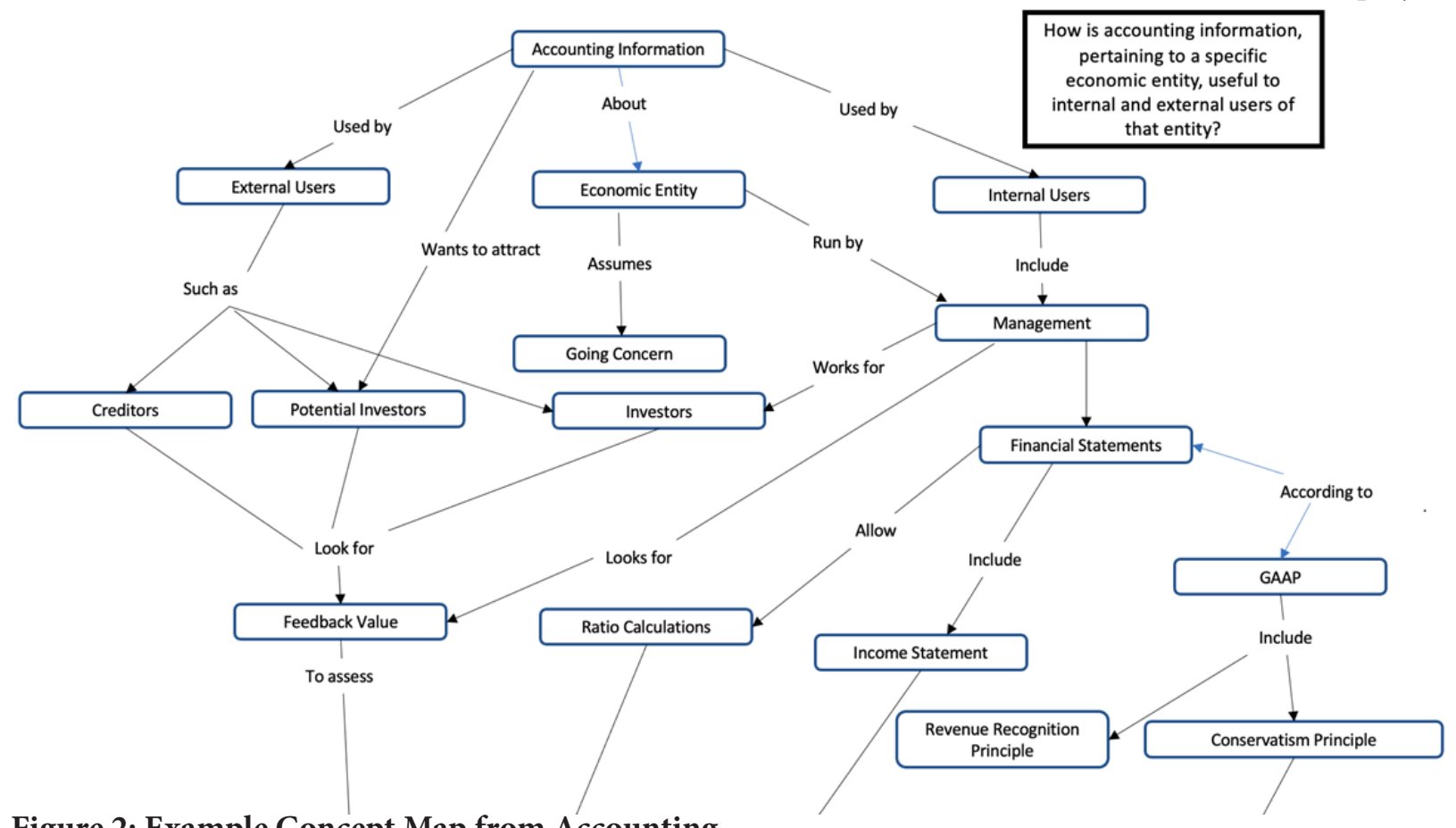

Figure 2: Example Concept Map from Accounting

Reproduced from Light et al., 2009, p. 72 
they may not understand the larger context-that is, when they should be used and why they can clarify the allocation of resources. In short, students at this point do not exhibit mastery, because they lack a full appreciation of when and why-in addition to the more basic what and how.

As discussed in Principle 2 (P2), business school curricula are structured to provide component skills in the foundation courses. This compartmentalized approach has its advantages since students can build on their foundational knowledge in more specialized upper-level classes. The approach also has considerable disadvantages. A marketing major may learn how to launch a successful product, but has little understanding of:

- the role of credit policies to raise funds (finance)

- the role the economic outlook can have on a product's success (economics)

- the training that will be needed for the sales staff (human resources)

- the steps necessary to instill quality in the production line (operations management)

- the development of IT resources to track orders and hire new people (MIS)

- the logistics necessary to get it to the customer in a reasonable time (supply chain)

The traditional hierarchical (and siloed) business school progression can endanger, therefore, the achievement of mastery.

A complementary approach could be the selective use of integrative classes-consistent with a senior capstone. Students could be presented with a challenge (and potentially a real client) and be expected to research the business concepts that are required to achieve the goal (DeConinck \& Steiner, 1999). Students would be expected to conduct statistical analysis, project hiring, marketing development, financial statement analysis, economic forecasting, and other relevant tasks to answer the presented challenge. Such an approach could provide a greater context for the concepts, as well as practice integration across disciplines.

Researchers have also found concept mapping a valuable formative technique, because it encourag-

Table 3: The Effects of Mastery

\begin{tabular}{|c|c|c|c|}
\hline & & \multicolumn{2}{|c|}{ Business Competence/Skills } \\
\hline & & Incompetence & Competence \\
\hline \multirow{2}{*}{ 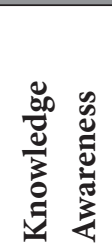 } & Unconscious & $\begin{array}{l}\text { I don't know } \\
\text { what I don't know } \\
\text { (Freshman) }\end{array}$ & $\begin{array}{l}\text { I don't know } \\
\text { what I know } \\
\text { (Faculty) }\end{array}$ \\
\hline & Conscious & $\begin{array}{l}\text { I know what I don't know } \\
\text { (Upperclassman) }\end{array}$ & $\begin{array}{l}\text { I know what I know } \\
\text { (New Faculty) }\end{array}$ \\
\hline
\end{tabular}

Adapted from Ambrose et al. (2010), p. 97 es students to consider the relationships between concepts. Maps also enable the instructor to identify misconceptions in the students' mental models. This exercise can be expanded: students can examine, compare/contrast, and comment on the concept maps of other teams. In the above example (Figure 2 ), an accounting student developed a concept map as a part of a learning portfolio (Light et al., 2009). The process to develop such a model is highly reflective and encourages the student to consider how different concepts interact and relate.

Although mastery is a goal that all business faculty should aspire to for their students, an instructor's mastery can be a two-edged sword when attempting to create an effective learning environment. In an adaptation of concepts presented in Ambrose et al. (2010), Table 3 explores how competence and connew and experienced faculty. New college students are in a state of unconscious incompetence--not knowing what they do not know regarding business concepts and skills. As the student progresses, however, they become increasingly aware of what they do not know (conscious incompetence) (Broadwell, 1969). In contrast, new faculty members recall not only what they know, but also why they know it (conscious competence). At some point, however, faculty members lose that context, and concepts become increasingly self-evident. They have reached unconscious competence, where concepts have become "obvious". At this point, faculty have subsumed their understanding of "how" with the more contextual (and experiential) understanding of "why" and "when".

Unconscious competence is a considerable problem, especially among more senior faculty members. Unconscious competence can result in a lack of faculty empathy when students fail to understand "the obvious". Students simply cannot achieve the mastery that faculty exhibit every day, since students lack the experience and context that faculty achieve through repeated interaction with the material. Faculty need to be aware of this bias when working with students, or they can inhibit student motivation and undermine student potential. This is yet another example of how faculty need to create a sense of community sciousness interact, affecting college students, and

\section{Business Competence/Skills}

. 
in a business school class and ensure that students feel comfortable in asking questions when they are confused. (Berkow, 2021)

One tool used in business schools that promotes students' understanding of integration is a simulation game. Some games are sophisticated and complex, beginning with creating a business plan and then implementing that plan, using teamwork and communication skills (George \& Delcore 2012). One example is the ERPsim game where students can learn about business processes by playing a simulation game on an enterprise system. This system covers all business aspects from accounting to supply chain to selling, giving the students an integrated view of how a company works. A typical business student can use their knowledge of the different functions in a business to make decisions on the game. (Robbins, 2014) Study-abroad programs also facilitate students' understanding of businesses' "big picture", by exposing them to different cultures and business habits (George \& Delcore, 2012). Both authors have conducted numerous study-abroad programs and are amazed at the intellectual growth and maturity that students undergo in a relatively short period of time. Many universities, such as the authors', make use of guest speakers from industry. These not only form connections to perhaps past alumni and companies, but also enable students to have a real perspective on how a business works. Using these speakers as role models, students begin to gain an understanding of how it all fits together.

To reinforce integrating the business skills, students should be required to write and explain their thought processes when solving problems, helping them to describe what they have learned. A large study involving 400 students at a business-accredited college showed that communication increased students' problem-solving skills. They were able to define problems more clearly, work better with data and create superior recommendations (Zhao \& Alexander, 2004). Encouraging students to communicate their knowledge of business forces them to probe the depth of that knowledge and fill in any gaps that are missing, resulting in a more complete understanding.

\section{Principle 5: Goal-directed practice cou- pled with targeted feedback are critical to learning.}

For unconsciously incompetent students, the clarity of a course's goals may be difficult to understand. In an introductory programming course, for example, a goal for a particular course segment might be looping. To the instructor, this might make perfect sense (how/what/why/when are easily understood), but the level of understanding is less clear to a student. An educator might expect students to:
- Understand the format of loop.

- Create a loop that prints out the numbers 1 through 10.

- Sum the elements of an array, regardless of size.

- Create an algorithm that finds the square root of any real number.

The above proceed from concrete to conceptual, moving from knowing (memorization/how/what) to doing (analysis and synthesis of concepts/why/ when). The last two goals do not even mention loops, requiring the student to identify that iteration is needed.

Without guidance, students studying for a test will tend to gravitate toward learning the first two, given that they are the easiest and can be memorized. Educators, however, will tend to gravitate toward the latter two, because they are more conceptual and involve higher order thinking. This dichotomy results in the comment: "The exam was completely different from what we did in class."

Such a contrast in focus results from a lack of goal clarity-that is, that an instructor clearly delineates what students must accomplish to earn a particular grade. Stating goals and learning outcomes in terms of what students must be able to do-not in terms of what they need to know-may help direct students' efforts. Once a difficult goal has been clearly specified, however, the student will need:

- Safe opportunities to practice and fail

- Feedback from the instructor on how the student can improve

- Moral support in achieving the goal

Practice is critical. The skills and mastery that are often needed in today's businesses are more analogous to learning to play the guitar than memorizing multiplication tables. The amount of practice needed to master a concept is often underestimated by both students and faculty.

Unfortunately, the predominant grading paradigm in many business schools does not easily lend itself to instructor goal setting. Business schools tend to rely on partial credit to determine a student's final grade. Students who want to earn an 'A' but do poorly on an early exam, may find they have no recourse in achieving their goal.

An assessment approach that strongly contrasts with partial credit is specifications grading (SG) (Nilson, 2015; Nilson, 2016). Under SG, the instructor sets increasingly challenging goals for students who want to achieve higher letter grades. All assignments under SG are graded as "complete," "pending," or "not complete". In one SG approach, students can choose the number of projects they want to complete-the more projects, the higher the grade. In another approach, students might be given the option to complete a basic project for a ' $\mathrm{B}$ ' or a ' $\mathrm{C}$ ', but students seeking an ' $\mathrm{A}$ ' would be required to complete a more 
rigorous project. These examples illustrate how SG encourages students to set goals and strive to achieve them. Students who are less interested in the material, however, can opt to complete lesser assignments in exchange for a lower grade.

Exploring SG is perhaps especially important for business schools, since the partial credit grading paradigm does not reflect the real world:

"[In college], we had to show our work. If, in our haste to complete the problem, we made a simple math error that led to an incorrect numerical answer, yet in showing our work we demonstrated that conceptually we knew how to do the problem, we frequently received partial credit (maybe even most of the credit)....If we complete a financial calculation in the business world and get the wrong numerical answer, even if we largely applied the correct methodology, our answer is still simply wrong. As a matter of fact, it may not just be wrong - it could lead to material financial losses for the company we work for if it is not caught in time. Rather than receiving any positive partial credit for the work we have done, we very well could receive full blame for the wrong answer" - (Reinsurance Group of America, 2017).

Specifications grading reinforces the idea that competence and masterly should be students' goalsnot just earning sufficient points to pass an exam. Although specifications grading is not widely used, business school faculty should explore alternativesespecially if these alternative assessments approaches map better to students' real-life assessments.

Receiving constructive feedback-from either an instructor or the relevant environment-is one of the most effective mechanisms for fostering learning. Whether it be from hitting the ground when learning to ride a bike, a girlfriend who tells us our shirt does not match our pants, or a college professor who comments on her students' learning reflections, timely and corrective feedback can be immensely valuable in guiding students' learning efforts.

But feedback alone is less effective than providing an opportunity for students to integrate feedback into their work. SG integrates feedback into the learning and assessment process. To return to the above example, if a student falls below the $90 \%$ on one exam, she would receive a "pending" score. After the instructor meets with the student to provide feedback on her misconceptions, the instructor can provide the student another opportunity to succeed by giving a makeup exam. If a student's project fails to complete the required specifications, students can also be given a chance to revise his work and resubmit for credit. Using these approaches, SG provides opportunities for students to receive targeted feedback from an instructor and learn from their mistakes.

Specifications grading is a powerful approach for integrating goal-directed practice and feedback.
The authors have integrated it into their courses and found it has opened up new avenues for providing feedback and encouraging students to strive toward deeper learning.

\section{Principle 6: Students' current level of development interacts with the social, emotional, and intellectual climate of the course to impact learning.}

In Principle 4 (P4), we noted that faculty's unconscious competence could blind them to students' lack of understanding. In addition to this dichotomy in intellectual maturity, a gap is also likely present for social and emotional maturity. Early in the course, students will have a natural reluctance to ask questions, since they lack conceptual understanding and the instructor's response is an unknown. Students will fear being mocked by peers or the instructor, and it will take only one such incident to shut down future inquiries.

To create a supportive learning environment, faculty must strive to make uncertainty safe (Ambrose et al., 2010) by not only encouraging questions, but providing students a basis for doing so. Simply asking, "Are there any questions?" will rarely be successful. Instead, faculty might provide scaffolding options that create a foundation for insightful questions. Earlier in this paper, we described the RAP (readiness assurance process), in which students are given an individual quiz, which is then followed up with a collaborative quiz (Williams \& Williams, 2011). Groups must then reach a consensus answer. The collaborative discussion provides a basis for students to compare their individual answers with their team's collaborative response. Questions then result from deviations of their understanding (Michaelsen et al., 2004). Results from collaborative quizzes suggest that they may be able to replace instructor-led discussions on material, and additionally provide opportunities for intellectual arguments with similar outcomes (Quinn \& Eckerson, 2010).

Student teams can improve the class's overall climate. After assigning a problem at the start of class, the faculty member might select one team to present their proposed solution. Other teams can then comment on the approach. If some concepts are still unclear, the instructor can give a mini lecture to clarify the outstanding concepts. This approach can dramatically improve the effectiveness of lecture, since the knowledge transfer occurs after the students have worked within the domain, and therefore within the learning context. Students will also feel more confident in and capable of asking questions, since they will have a stronger basis for their inquiry. Teams also have the benefit of encouraging students to be tolerant of others' opinions and talents, a development necessary for a deep learning environment (Chickering \& Reisser, 1993). 
Instructors often complain about student inattention during class, especially involving the use of laptops and mobile phones. The emotional maturity levels of students do support instituting limits on the use of technology during class, and such distractions can interfere with other students' learning. But repeated violations of the policy may be a warning about the effectiveness of instructor's learning environment. Students who are motivated to learn should be paying close attention and be eager to work on tasks in the classroom (Williams \& Williams, 2011). Distracted students may be communicating that class is boring, lacks relevance, and is too faculty centric. In addition to punitive measures, the instructor should also explore options for involving students more in the learning process.

Ambrose et al. (2010) refer to the Chickering Model of Student Development, which includes establishing identity. Students who are comfortable with their identity are better at learning without intimidating this identity. A new business school class on diversity in business at University of Delaware presents students with the history of how laws, regulations, and corporate policy differ along demographics.. In hopes that these future business leaders will provide equity in decision-making, the class strives to open their eyes to the past and current climate. Students' responses to this class are very favorable and the students remark that they never learned this material in any history class (Berkow, 2021). By students' being comfortable with their identity, they can then be free to develop their college and career path, freeing them to learn without constraints and deeply (Chickering \& Reisser, 1993).

\section{Principle 7: To become self-directed learners, students must learn to monitor and adjust their approaches to learning.}

The final piece of the learning puzzle is perhaps among the most important: the role of metacognition and reflection. Metacognition involves an awareness of one's thought processes. It is the conscious consideration by students of what they do (and do not) know. When given a problem to solve, metacognition involves the thoughtful consideration of why students selected a specific approach. Given students' predilection for surface learning techniques, student reflection may not occur without faculty encouragement. This section presents several practical suggestions for guiding faculty and encouraging students to reflect on their learning progress.

When given a mathematical problem, students have been conditioned to "plug and chug" the answer-that is, plug the numbers into an equation. The extent of metacognition, however, is minimal. Once the answer is calculated, students may fail to consider the implications (or purpose) behind the result. To encourage metacognition, one approach is to withhold information necessary to solve the problem. Within a finance class, for example, an instructor might ask students to research "The Rule of 72." Since the prompt includes no numbers, students will appropriately gravitate toward first understanding what it is. The Rule is simple (take 72 and divide by the interest rate to estimate the number of years for doubling one's money), but this opens the door to more conceptual follow-up questions:

- Why does the Rule work?

- Should the Rule be used to give financial advice? Why or why not?

Hence, the above questions encourage students to reflect beyond the simple math and consider broader policy issues around its use.

Incorporation of formative assessment approaches into a course can also provide opportunities for metacognition. Angelo and Cross' (1993) book Classroom Assessment Techniques is a trove of formative assessment approaches, many of which incorporate student reflection. In "The Muddiest Point," for example, students report their perception of the most confusing concept in the course to date. Faculty then dedicate the next class to reviewing the submitted items. This technique encourages students to reflect on their learning progress and identify their areas of weakness. It also can improve student perceptions of the instructor's supportiveness. Another formative approach is to integrate opportunities for students to iteratively retrieve and demonstrate knowledge through low- (or even no-) stakes "reflective tests" (Roedinger, 2014). The process of comparing a practice exam's correct answer with their response can be a highly formative process that encourages reflection and questions.

Instructors commonly introduce a topic in lecture, then assign graded homework. This progression is problematic for several reasons. The lecture provides no opportunity for the students to practice before the graded homework is assigned, and students have received little feedback on the concept's pitfalls. Alternatively, instructors can encourage deep understanding by first giving them an opportunity to practice when feedback is readily available-i.e., during class. As an example, faculty might lecture on net present value. Instead of assigning homework outside of class, the instructor might allow students to work on the assignment during the last fifteen minutes of class (Catapano, 2019). This strategy allows the instructor to encourage questions and to provide preliminary feedback on the assignment. Greater integration of metacognitive processes and reflective practices will deepen student learning, as well as provide the skills necessary for students to learn after college.

Finally, instructors need to focus more on fostering students' intrinsic motivation than relying on extrinsic motivators (Bolkan \& Goodboy, 2010; 
Christophel, 1990; Deci \& Ryan, 2000). Faculty commonly leverage extra credit, added points on exams, and dropped quizzes to motivate students, but-in a larger context-these measures can act as demotivators for learning. As extrinsic motivators, partial and extra credit condition students to strive to understand only when they get something in return.

In contrast, instructors who foster students' intrinsic motivation have a greater chance of instilling a greater love of learning. Intrinsic motivation has been defined as, "the inherent tendency to seek out novelty and challenges, to extend and exercise one's capacities, to explore, and to learn" (Deci \& Ryan, 2000 , p. 70). Instructors can take simple steps to foster that internal drive to learn. Principle 3 (P3) reviews three accessible levers for nurturing intrinsic motivation. Principle 5 (P5) describes how specification grading can encourage goal-directed learning and provide opportunities for students to learn from mistakes. Both approaches can create an accessible environment for students, encourage them to become self-directed learners, and strive for even deeper forms of understanding.

\section{Conclusions}

The purpose of this essay is to explore seven principles that can deepen student learning. These principles are not tied to a specific pedagogy or teaching approach and can be adopted within any business school discipline.

Children experience the joy that comes from intellectual exploration, but somehow many lose it along the way. By the time that child reaches college, learning often has become something to tolerate, not to savor. Faced with this challenge, how can faculty encourage business students to be intellectually curious?

Clearly, one of the highest aspirational goals faculty members can achieve is to see their students become lifelong learners, an essential attribute of any effective business leader. The challenge, of course, is that this goal does not come easily. Students must devel-

\section{References}

Ambrose, S. A., Bridges, M. W., DiPietro, M., Lovett, M. C., Norman, M. K., \& Mayer, R. E. (2010). How learning works: Seven Research-based Principles for Smart Teaching. San Francisco, CA: Jossey-Bass.

Bandura, A. (1997). Self-efficacy: The Exercise of Control. San Francisco, CA: Freeman.

Berkow, K. (Host). (2021, September 13). Fostering community in the classroom with Wendy Smith. (no. S2E1) [Audio podcast episode] In On Cultivating Student Engagement in Higher Ed. https://podcasts.apple.com/us/podcast/on-cul- op their prior knowledge (P1) and organize it to create a solid foundation (P2). This foundation sets the stage for future learning, since it enables students to succeed, which builds their confidence and intrinsic motivation (P3). Development of learning includes the setting of goals (P4), achieving those goals, and eventual achievement of mastery in areas of interest (P5). By building confidence and mastery, students learn to manage the relevant learning environment (Principle 6), creating a space for deep learning and embrace self-directed learning (Principle 7).

There are lessons in these seven principles for both aspiring and current business leaders in that they act as signposts for personal learning and development. We maintain that deep learning is a necessary condition for students to become self-directed learners, but also that these principles apply to not only business college students, but also to any member of the business community.

Although Ambrose et al.s seven principles offer an intriguing framework for instilling deep-learning, more empirical data is needed on their relevant efficacy. The principles would lend themselves well to experiments, especially ones that explore deep learning over shallow approaches. We encourage research in these areas.

In today's competitive, fast-paced, and global environment, students need to solve problems, think critically and analytically, and communicate effectively. These developed skills are more attainable using student-centered pedagogies, and arguably cannot be achieved through lecturing. We urge faculty to rethink their educational expectations: what impact are they really having on their students? What do they really expect that their students can do six months after class ends? Is that good enough? In the spirit of the three-part definition of learning, we encourage faculty to expect and strive for deeper learning. We encourage faculty to engage students' interest. Finally, we encourage faculty to expect and enable student mastery by creating a learning environment that is challenging and rewarding.

tivating-student-engagement-in-higher-ed/ id1538294450

Berkow, K. (Host). (2021, September 20). Including race, bias, and inequity in the business curriculum with Jennifer Joe and Anu Sivaraman. (no. S2E2) [Audio podcast episode]. In On Cultivating Student Engagement in Higher Ed. https://podcasts.apple.com/us/podcast/on-cultivating-student-engagement-in-higher-ed/id1538294450

Biggs, J. (2003). Teaching for Quality Learning at University: What the Student Does, $2^{\text {nd }}$ ed.. Berkshire, England: McGraw-Hill. 
Broadwell, M. (1969, February). Teaching for Learning (XVI). Retrieved from Gospel Guardian: http://wordsfitlyspoken.org

Catapano, J. (2019). Classroom management: Give students class time to work. Retrieved February 2019, from TeachHub: http://www.teachhub. com/classroom-management-give-studentsclass-time-work

Chan, C. \& Murphy, M. (2010). Active-based keyskills learning in engineering curriculum to improve student engagement. In M. K. Iskander, Technological Developments in Education and Automation (pp. 79 - 84). Netherlands: Springer. https://doi.org/10.1007/978-90-481-3656-8_16

Chickering, A. \& Reisser, L. (1993). Education and Identity, $2^{\text {nd }}$ Edition. San Francisco: Jossey-Bass.

Crooks, T. J. (1988). The impact of classroom evaluation practices on pupils. Review of Educational Research, (pp. 438 - 481). https://doi. org/10.3102/00346543058004438

Dehler, G., Beatty, J., \& Leigh, J. (2010). From "good teaching" to "scholarly teaching": Legitimizing management education and learning scholarship. In C. Wankel, \& R. DeFillippi (eds.), Being and Becoming a Management Education Scholar (pp. 95 - 118). Charlotte, NC: Information Age Publishing.

Fink, D. (2013). Creating Significant Learning Experiences: An Integrated Approach to Designing College Courses. San Francisco, CA: Jossey-Bass.

Ford, M. E. (1992). Motivating Humans: Goals, Emotions, and Personal Agency Beliefs. Newbury Park, CA: Sage Publications, Inc. https://doi. org/10.4135/9781483325361

Freeman, S., Eddy, S., McDonough, M., Smith, M., \& Wendero, M. (2014). Active learning increases student performance in science, engineering, and mathematics. PNAS, (pp. 8,410-8,515). https://doi.org/10.1073/ pnas.1319030111

Freire, P. (1990). Pedagogy of the Oppressed. New York: Continuum.

George, B. \& Delcore, N. (2012). Integration: An elusive concept. Journal of Instructional Pedagogies, 7, (pp. 1 - 13).

Hansen, D. (1989). Lesson evading and dissembling: Ego strategies in the classroom. Journal of Education, 97(2), (pp. 184 -208). https://doi.org/10.1086/443921

Jonassen, D. H., Mayes, T., \& McAleese, R. (1993). A manifesto for a constructivist approach to uses of technology in higher education. In T. Duffy, J. Lowcyk, \& D. Jonassen (eds.), Designing Environments for Constructive Learning (pp. 231 - 247). Berlin: Spring-Verlag. https://doi.org/10.1007/9783-642-78069-1_12

Kuh, G. D., Kinzie, J., Schuh, J. H., Whitt, E. J., \& Associates, (2005). Student Success in College, Creating Conditions that Matter. San Francisco: Wiley.

Light, T., Sproule, B., \& Lithgow, K. (2009). Connecting Contexts and Competencies: Using Eportfolios for Integrative Learning. In D. Cambridge, B. Cambridge, \& K. Yancey (eds.), Electronic Portfolios 2.0: Emergent Research on Implementation and Impact (pp. 69 - 79). Sterling, VA: Stylus.

McKeachie, W. J. (1990). Research on college teaching: The historical background. Journal of Educational Psychology, (pp. 189 - 200). https://doi.org/10.1037/0022-0663.82.2.189

McKendree, J. (1990). Effective feedback content for tutoring complex skills. Human-Computer Interaction, 5(4), (pp. 381 - 413). https://doi.org/10.1207/s15327051hci0504_2

Michaelsen, L., Knight, A., \& Fink, D. (2004). Team-based Learning: A Transformative use of Small Groups in College Teaching. New York: Stylus Publishing.

Nilson, L. (2015). Specification Grading: Restoring Rigor, Motivation Students, and Saving Faculty Time. Stylus Publishing.

O’Neil, J. (1995). Our schools as learning organizations: A conversation with Peter Senge. Educational Leadership, (pp. 20 - 23).

Reinsurance Group of America. (2017, May 25). There is no partial credit in real life: A meditation on actuarial bias in group pricing. Retreived from https://www.rgare.com/ knowledge-center/media/articles/there-is-nopartial-credit-in-real-life.

Robbins, R. (2014). Clarifying the SAP ERPsim experience. Americas Conference on Information Systems, Savannah, (pp. 1 - 13).

Roedinger, H. L. (2014, July 18). How tests make us smarter. New York Times, p. SR12.

Schwartz, M., Sadler, P., Sonnert, G., \& Tai, R. (2008). Depth versus breadth: How content coverage in high school science courses relates to later success in college science courses. Science Education, 93(5), (pp. 798 - 826). https://doi.org/10.1002/sce.20328

Shuell, T. J. (1986). Cognitive conceptions of learning. Review of Education- 
al Research, (pp. $411-436)$. https://doi. org/10.3102/00346543056004411

Singleton-Jacson, J.A, Jackson, D.L, \& Reinhardt, J. (2010). Students as Consumers of Knowledge: Are They Buying What We're Selling? Innovation Higher Education, 35(4), 343 - 358. https://doi.org/10.1007/s10755010-9151-y

Sotto, E. (1994). When teaching becomes learning: A theory and practice of teaching. London: Continuum.

Williams, K., \& Williams, C. (2011). Five key ingredients for improving student motivation. Research in Higher Education Journal,
$12,1-23$.

Zhao, J. \& Alexander, M. (2004). The Impact of Business Communication Education on Students' Short- and Long-Term Performances. Business Communication Quarterly, 67(1), (pp. 24 - 40). https://doi.org/10.1177/1080569903261995

\section{Review}

This article was accepted under the strict peer review option. For futher details, see the descriptions at:

http://mumabusinessreview.org/peer-review-options/

\section{Authors}

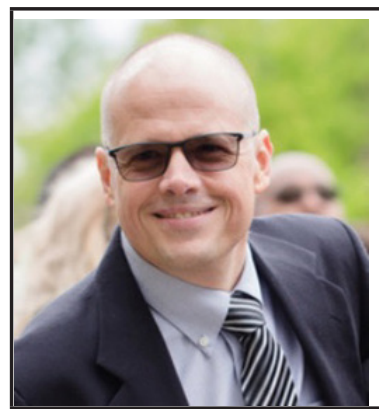

Mark A. Serva is an associate professor of management information systems at The University of Delaware. He has published research in Decision Sciences, IEEE Transactions on Engineering Management, Communications of the Association for Information Systems, and many other journals. He is the former Director for UD's Institute for Transforming Undergraduate Education (ITUE) and currently serves on the leadership board for PANPBL, a leading international organization for advocating the use of active learning pedagogies. He is the recipient of a number of many teaching awards, and is an active consultant in the improvement of student learning, teaching improvement, and alternative approaches for assessment.

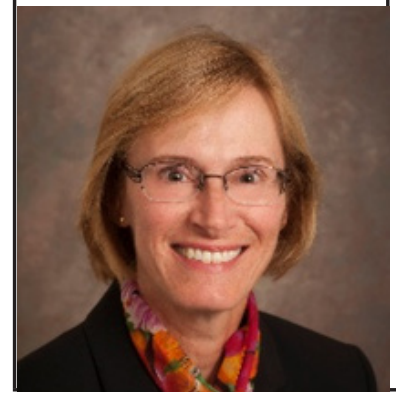

Ellen F. Monk earned her Ph.D. in the Information Systems and Computing Department at Brunel University. She is an associate professor and associate chair, MIS, in the Department of Accounting and Management Information Systems in the Lerner College of Business at the University of Delaware. Her research interests in the field of education include enterprise resource planning systems and blended learning. Her research has been published in Journal of Information Systems Education, Education and Information Technologies, among others, and she is co-author of Concepts in Enterprise Resource Planning Systems, Problem-Solving Cases in Microsoft Access and Excel, and other texts. 